\title{
Escalada Tarifária e Exportações Brasileiras da Agroindústria do Café e da Soja
}

\author{
Francine Rossi Rodrigues ${ }^{1}$ \\ Heloisa Lee Burnquist ${ }^{2}$ \\ Cinthia Cabral da Costa $^{3}$
}

\begin{abstract}
Resumo: A escalada tarifária, em que o emprego de tarifas de importação sobre componentes ou matéria-prima é mais baixo e aumenta progressivamente para bens semifinais ou finais, estimula a importação de produtos primários em detrimento dos processados. Este artigo mensura os ganhos para o Brasil com a eliminação da escalada tarifária para produtos do café na União Européia (UE), e da soja na China e na UE, comparando esses resultados com os de uma redução da escalada proposta na Rodada Doha da OMC (Organização Mundial do Comércio). Para tanto, foram simuladas reduções tarifárias e quantificados os impactos comerciais com uma modelagem de equilíbrio parcial. Os resultados indicam que as negociações sob a rodada Doha da OMC poderão reduzir a escalada tarifária que incide sobre produtos do café na UE e da soja na China e na UE, no entanto sem a eliminar, para o que seriam necessários cortes tarifários mais elevados. Os impactos comerciais se mostraram maiores na simulação de eliminação da escalada tarifária do que na de uma redução, conforme esperado. Quantificou-se o volume de comércio que o Brasil deixaria de ganhar no caso da adoção da proposta de Doha para corte da escalada. Na UE, o aumento das importações dos produtos brasileiros processados do café e da soja poderia ser 75,4\% maior com a eliminação da escalada tarifária do que com a redução conforme Doha.
\end{abstract}

Palavras-chave: Escalada tarifária, China, UE, soja, café.

Abstract: The tariff escalation, where the import duties on components or raw materials are lower, and move progressively higher on semi-finished goods upwards to the finished goods, stimulates the imports of primary commodities rather than processed products. This article measures the gains to Brazil with the elimination of the tariff escalation

$1 \quad$ Analista de mercados da ED\&FMan. E-mail: francine.rodrigues@mansugar.com.br

2 Professora associada do Deas/Esalq/USP. E-mail: hlburnqu@esalq.usp.br

3 Pesquisadora do Centro de Instrumentação Agrícola da Embrapa. E-mail: cinthia. cabral.da.costa@gmail.com 
for coffee products in the European Union (EU), and soybean products in China and in the EU, comparing these results with those of an escalation reduction proposed in the Doha Round of the WTO (World Trade Organization). For that purpose, tariff reductions have been simulated and the impact upon trade has been evaluated with the application of partial equilibrium modeling. The results indicate that trade under the Doha round of the WTO can reduce the tariff escalation although it is not phased out, which would require greater tariff cuts. The impacts upon trade have been higher in the simulation of an elimination of tariff escalation than in its reduction, as expected. It was possible to quantify the trade flows that Brazil would not gain if the Doha proposal for tariff escalation reduction was adopted. The EU imports of coffee and soybean processed products from Brazil could be 75.4 percent higher with the elimination of the tariff escalation than under its reduction according to Doha negotiations.

Key-words: Tariff escalation, China, EU, soybean, coffee.

Classificação JEL: F13.

\section{Introdução}

Embora tenha sido objeto de negociações comerciais do Acordo Geral sobre Tarifas e Comércio (GATT) e da OMC (Organização Mundial do Comércio), o emprego de instrumentos como a escalada tarifária continua restringindo a importação de produtos com maior valor agregado. O conceito de escalada tarifária foi introduzido em meados da década de 60 para identificar uma estrutura tarifária em que a taxa é tanto maior, quanto mais alto o valor agregado do produto sobre a qual esta incide (BALASSA, 1965).

O emprego de tarifas de importação crescentes conforme aumenta o grau de processamento de um produto estimula a importação e a disponibilidade de insumos com baixa ou nenhuma incidência de tarifas, notadamente de produtos agrícolas primários, ao mesmo tempo em que dificulta o acesso a mercados para produtos com maior valor adicionado (ELAMIN e KHAIRA, 2003; LINDLAND, 1997; ORGANIZATION FOR ECONOMIC CO-OPERATION AND DEVELOPMENT - OCDE, 1996; UNITED NATIONS CONFERENCE ON TRADE AND DEVELOPMENT - UNCTAD, 2003).

As evidências apresentadas pela maior parte dos trabalhos consultados sugerem que alguns produtos derivados de agrícolas e com maior nível de processamento tendem a ser mais protegidos no comércio internacional que suas matérias-primas e/ou aos produtos intermediários. Em Nassar, Arashiro e Jank (2007), por exemplo, a incidência de escalada tarifária é identificada sobre cadeias agrícolas, tais como café, soja, palma, trigo, cacau, milho e tabaco em diferentes mercados. 
A escalada tarifária, embora aplicada tanto por países desenvolvidos quanto por países em desenvolvimento, parece incidir preponderantemente em cadeias agrícolas de interesse para exportação para a maioria dos países em desenvolvimento (ELAMIN e KHAIRA, 2003). Ademais, nos países onde produtos agrícolas têm participação importante na composição das exportações, essas podem ser as mais prejudicadas pelo emprego da escalada tarifária. Considera-se que países essencialmente especializados na produção de matérias-primas e produtos agrícolas primários se defrontam com barreiras comerciais mais elevadas quando tentam aumentar sua participação em mercados de produtos com maior processamento (UNCTAD, 2003).

Estudos sobre escalada tarifária identificam dois métodos básicos de análise: escalada tarifária nominal (Tariff Wedge - TW) e taxa de proteção efetiva (Effective rate of protection - ERP). A escalada tarifária nominal somente mostra se as tarifas ad valorem aumentam (ou não) conforme o nível de processamento dos produtos, mas não provê informação quanto à magnitude pela qual a indústria de processamento é de fato protegida (NASSAR, ARASHIRO e JANK, 2007). Por sua vez, a medida da taxa de proteção efetiva é aplicada à mensuração da taxa de proteção à indústria doméstica no país importador, através da porcentagem pela qual a estrutura tarifária aumenta o valor adicionado pela indústria de produtos domésticos equivalentes aos importados. No entanto, as negociações multilaterais sob o âmbito da OMC têm se limitado às tarifas nominais, sem considerar a proteção efetiva proporcionada aos produtos.

Sob a Rodada Doha, rodada de negociações de comércio multilateral em evolução no âmbito da OMC (Organização Mundial do Comércio), sugerese que paralelamente à definição de cortes tarifários gerais sobre produtos agrícolas (fórmula de corte em bandas), exista um mecanismo adicional de ataque específico à incidência de escalada tarifária. O texto das negociações agrícolas de julho de 2008 sugere que a prática de escaladas tarifárias seja eliminada, definindo que sobre a tarifa de um produto processado não deverá incidir o corte sugerido na banda em que a tarifa do mesmo se encontra, e sim o corte sugerido às tarifas dos produtos da banda imediatamente superior. Para tanto, foram listados produtos para aplicação da fórmula de eliminação específica à escalada tarifária, tais como frutas, vegetais, café e oleaginosas, alguns cereais e cacau, produtos de interesse para o comércio exterior brasileiro (WTO, 2008).

A restrição comercial a produtos agroindustriais na forma da aplicação de escalada tarifária nos mercados importadores tende a desestimular atividades de processamento nos países exportadores e a promover a produção e consequente exportação de commodities primárias a serem processadas nos mercados protegidos. Dessa forma, transferem-se para esses mercados os benefícios econômicos que seriam proporcionados pelas atividades de processamento, tais como as agroindústrias (ELAMIN e KHAIRA, 2003). 
O objetivo do presente artigo é mensurar os ganhos que poderiam ser obtidos pelo Brasil com a eliminação da escalada tarifária em produtos das cadeias selecionadas (do café no mercado da União Européia, e da soja na China e na União Européia), bem como comparar tais resultados com os da redução da escalada proposta no documento mais recente da Rodada Doha. Para tanto, simula-se a aplicação da fórmula proposta em Doha para ataque específico à escalada tarifária, assim como um exercício de eliminação da escalada tarifária. Em ambas as situações, após as simulações de alterações de política comercial, quantificam-se os impactos sobre o comércio brasileiro das cadeias analisadas.

Verifica-se que a redução da escalada tarifária incidente sobre o comércio brasileiro favorece as exportações de produtos processados do Brasil, relativamente às de commodities agrícolas primárias, contribuindo para os ganhos de comércio.

Acredita-se que a análise conduzida provê subsídios relevantes para a elaboração de estratégias de negociação comercial de reduções tarifárias para produtos de interesse ao Brasil. Trabalhos dessa natureza podem ser particularmente interessantes quando se verifica que a demanda por redução/ eliminação da escalada tarifária, em particular, não é sempre acompanhada de propostas concretas de solução.

O trabalho está organizado de forma a apresentar, além da presente introdução, uma seção com a metodologia, que introduz o conceito de proteção efetiva versus escalada tarifária, seguindo-se modelo conceitual e a identificação das taxas envolvidas nos cálculos. A seguir, são apresentados os resultados, comparando-se o contexto em que as mudanças propostas na Rodada Doha para a questão das escaladas tarifárias são introduzidas com a eliminação total da escalada tarifária. Os resultados são apresentados a seguir, e, por fim, há considerações gerais.

\section{Metodologia}

Uma estrutura de escalada tarifária ocorre quando as tarifas de importação aplicadas aumentam com o grau de processamento envolvido na obtenção de um produto ao longo de uma cadeia produtiva. A forma como as tarifas são administradas nos diferentes estágios de processamento provê incentivos diferenciados à produção local de bens processados: tarifas relativamente mais elevadas sobre produtos processados que sobre os não processados implicam aumento do valor adicionado para bens processados similares domésticos, estimulando atividades de processamento em mercados protegidos e aumentando a demanda por bens primários.

Os estudos sobre escalada tarifária mencionam dois métodos de identificação e análise: escalada tarifária nominal (Tariff Wedge - TW) e taxa de proteção efetiva (Effective rate of protection - ERP). 
A partir das tarifas nominais (que incidem sobre o preço de um produto no mercado doméstico), a escalada tarifária é identificada e mensurada pela diferença entre a que se aplica sobre o produto processado $\left(\mathrm{T}_{\mathrm{i}}\right)$ e aquela que recai sobre o insumo ao seu processo produtivo, ou sobre o produto com menor grau de processamento $\left(\mathrm{T}_{\mathrm{i}-1}\right)$, conforme indicação da fórmula (1):

$$
T W=T_{i}-T_{i-1}
$$

Sendo:

TW = Tariff Wedge nominal;

$\mathrm{T}_{\mathrm{i}}=$ tarifa equivalente ${ }^{4}$ ad valorem do produto com grau de processamento i;

$\mathrm{T}_{\mathrm{i}-1}=$ tarifa equivalente ad valorem de produto com grau de processamento $\mathrm{i}-1$, empregado como insumo na produção do bem com grau de processamento i.

A escalada tarifária nominal somente mostra se as tarifas ad valorem aumentam ou não, conforme aumenta o grau de processamento dos produtos, mas não reflete o nível real de proteção incorporado em cada estágio de processamento (NASSAR, ARASHIRO e JANK, 2007).

A taxa de proteção efetiva possibilita a mensuração da taxa de proteção à indústria doméstica ou cadeia produtiva nos países importadores, como a porcentagem pela qual as tarifas podem aumentar o valor agregado da referida cadeia produtiva, por unidade de produto (LINDERT e PUGEL, 1996).

Balassa (1965) e Corden (1966) iniciaram uma discussão extensiva sobre a escalada tarifária e sua implicação em termos de acesso a mercados nas décadas de 60 e 70. Na literatura da teoria do comércio internacional, esses autores merecem menção pela contribuição à inserção das relações entre taxas tarifárias derivadas de relações de insumo-produto entre os produtos e pela contribuição para a identificação dos efeitos da estrutura tarifária total de uma cadeia produtiva sobre a alocação de recursos. Considera-se a teoria da proteção efetiva como uma aplicação da teoria de relações interindustriais à teoria do comércio.

Segundo Balassa $(1965)^{5}$, define-se taxa efetiva de proteção como uma medida do efeito total da estrutura tarifária sobre o valor adicionado, por unidade de produto em cada indústria, considerando-se que todos os produtos da referida cadeia produtiva - com maior ou menor grau de processamento, esses últimos empregados na produção dos primeiros - podem ser importados, e, portanto, sujeitos a uma tarifa. De outra forma, a taxa efetiva de proteção indica o diferencial entre o valor adicionado doméstico que é obtido mediante

4 Define-se uma tarifa equivalente como a tarifa fixa, transformada em ad valorem quando dividida pelo preço CIF de importação.

5 Balassa (1965) defende a necessidade de distinguir entre as taxas nominais e efetivas para a análise comparativa das tarifas comerciais. 
a imposição de tarifas, como uma porcentagem do valor adicionado obtido em uma situação de livre comércio.

A fórmula da taxa de proteção efetiva (ERP em inglês) pode ser expressa como na equação (2) apresentada por Corden (1966):

$$
E R P i=\frac{T_{i}-\sum_{i=1}^{n} a_{i-1} T_{i-1}}{1-\sum_{i=1}^{n} a_{i-1}}
$$

Sendo:

$T_{i}=$ tarifa ad valorem teórica ou efetivamente incidente sobre o produto processado de grau $i$, sendo que $i=1$...n;

$T_{i-1}=$ tarifas ad valorem teórica ou efetivamente incidentes sobre produtos com grau de processamento $i-1$, empregado como insumo no processo de produção do bem $i$;

$a_{i-1}=$ coeficientes que indicam a participação do valor unitário do insumo ou componente importável (i-1) no valor unitário do produto final (i) sob condições de livre comércio.

Seu cálculo, portanto, depende não só da tarifa incidente sobre o produto final de uma cadeia produtiva, como também do valor de cada insumo da produção sobre o valor total do bem final, juntamente às tarifas incidentes sobre eles.

A correspondência entre o valor da escalada tarifária medida em termos nominais e a taxa de proteção efetiva assume as seguintes formas, de acordo com Burman et al. (2001):

- Escalada tarifária nominal positiva: a taxa de proteção efetiva é positiva e assume valores crescentes, quanto maior a participação do custo da matéria-prima no preço do produto processado;

- Escalada tarifária nominal nula: a taxa de proteção efetiva tem valor positivo igual ao valor das tarifas nominais;

- Escalada tarifária nominal negativa (de-escalada): a taxa de proteção efetiva pode assumir valor negativo, com uma baixa participação do custo do insumo no preço do produto processado.

O estudo da escalada tarifária, segundo Nassar, Arashiro e Jank (2007), deve ser orientado à análise detalhada de cadeias produtivas, em vez de grupos agregados de produtos, pois sua avaliação requer a escolha de uma cadeia e a definição do que ela engloba. A seguir, procede-se à identificação das linhas tarifárias a serem analisadas. 
Sob a Rodada Doha de negociações comerciais, no que se refere ao ataque específico à escalada tarifária, sobre a tarifa de um produto processado não deverá incidir um corte sugerido na banda em que a tarifa do mesmo se encontra, mas deverá incidir o corte sugerido às tarifas dos produtos da banda imediatamente superior (WTO, 2008).

Quanto aos produtos para aplicação da fórmula de ataque específico à escalada tarifária, incluem-se frutas, vegetais, café e oleaginosas, além de cereais e cacau. O Quadro 1 resume a lista de produtos segundo a definição do texto mais recente da Rodada Doha de negociações. Nele estão descritos somente os produtos em análise pelo artigo. Os produtos são classificados conforme grau de processamento, como primários e processados.

Quadro 1. Classificação de cadeias agrícolas selecionadas segundo commodities primárias e produtos processados (nomenclatura do sistema harmonizado - HS) da WTO (2008).

\begin{tabular}{|l|l|l|}
\hline Cadeias & \multicolumn{1}{|c|}{ Primários } & \multicolumn{1}{c|}{ Processados } \\
\hline Café & 0901.11 - Café não torrado, & 0901.12 - Café não torrado, descafeinado; \\
& não descafeinado & 0901.21 - Café torrado, não descafeinado; \\
& & 0901.22 - Café torrado, descafeinado; \\
& & 0901.90 - Cascas, películas de café e sucedâ- \\
& & neos do café; \\
& & 2101.11 - Café solúvel, extratos, essências e \\
& concentrados de café; \\
& & 2101.12 - Preparações à base de extratos, es- \\
& sências e concentrados de café \\
\hline Soja & 12.01 - Soja para semeadura, & 1208.10 - Farinha de soja; \\
& ou outros grãos de soja, & 1507.10 - Óleo de soja bruto; \\
& mesmo triturados & 1507.90 - Óleo de soja refinado; \\
& & 23.04 - Resíduos da extração do óleo de soja \\
& & (farinhas, "pellets", bagaços e outros) \\
\hline
\end{tabular}

Fonte: WTO (2008).

Neste artigo quantificam-se os impactos de redução e da eliminação da escalada tarifária incidente sobre as exportações brasileiras das cadeias do café e da soja, por meio de simulações de cortes tarifários. Para tanto, simula-se a aplicação da fórmula proposta em Doha para ataque específico à escalada tarifária, assim como se analisa um exercício de eliminação da escalada tarifária. Em ambas as situações, após as simulações de alterações de política comercial, quantificam-se os impactos sobre o comércio brasileiro das cadeias analisadas.

Para a simulação de redução da escalada tarifária segundo a fórmula de Doha foram consideradas as tarifas nominais incidentes sobre as cadeias analisadas. Sobre as mesmas simula-se a incidência do corte tarifário segundo a fórmula em bandas e as determinações para ataque específico da escalada tarifária, de 
acordo com o texto mais recente das negociações agrícolas de Doha (Tabela 1 com as determinações para países desenvolvidos e Tabela 2, para países em desenvolvimento).

Tabela 1. Bandas e respectivos cortes tarifários segundo o texto mais recente da negociação agrícola sob a Rodada Doha para países desenvolvidos.

\begin{tabular}{ccc}
\hline Bandas & Cortes - fórmula geral & Cortes - escalada tarifária \\
\hline $0 \%<\mathrm{T} \leq 20 \%$ & $50 \%$ & $57 \%$ \\
$20 \%<\mathrm{T} \leq 50 \%$ & $57 \%$ & $64 \%$ \\
$50 \%<\mathrm{T} \leq 75 \%$ & $64 \%$ & $66-73 \%$ \\
$\mathrm{~T}>75 \%$ & $66-73 \%$ & $72-79 \%$ \\
\hline
\end{tabular}

Nota: T representa as tarifas nominais.

Fonte: WTO (2008).

Tabela 2. Bandas e respectivos cortes tarifários segundo o texto mais recente da negociação agrícola sob a Rodada Doha para países em desenvolvimento.

\begin{tabular}{ccc}
\hline Bandas & Cortes - fórmula geral & Cortes - escalada tarifária \\
\hline $0 \%<\mathrm{T} \leq 30 \%$ & $33 \%$ & $38 \%$ \\
$30 \%<\mathrm{T} \leq 80 \%$ & $38 \%$ & $43 \%$ \\
$80 \%<\mathrm{T} \leq 130 \%$ & $43 \%$ & $44-49 \%$ \\
$\mathrm{~T}>130 \%$ & $44-49 \%$ & $50-55 \%$ \\
\hline
\end{tabular}

Fonte: WTO (2008).

O fim da escalada representa a eliminação da diferença entre as duas tarifas (incidente sobre o produto com maior e menor grau de processamento, respectivamente) em termos de tarifa efetiva. Isso não significa que as tarifas são zeradas, mas que a tarifa do produto processado é estabelecida como sendo menor ou igual à do produto com menor grau de processamento.

A partir das tarifas efetivas incidentes sobre os produtos das cadeias em estudo nos mercados analisados, simula-se uma eliminação da escalada tarifária. A seguir, calculam-se as tarifas nominais equivalentes às efetivas (representando o fim da escalada) para posterior simulação do impacto comercial.

Os dados referentes a tarifas, tanto as nominais quanto as efetivas ${ }^{6}$, foram obtidos do trabalho de Nassar, Arashiro e Jank (2007), conforme Tabelas 3 e 4.

6 Vale uma ressalva com relação aos dados dessas tarifas. Embora tenham sido empregadas em Nassar, Arashiro e Jank (2007) como tarifas aplicadas, nos casos analisados (tarifas definidas na UE sobre os produtos da soja e do café e na China sobre os produtos da soja) as tarifas consolidadas (que são aquelas efetivamente consideradas nas rodadas de negociação sob a OMC e que precisam então ser consideradas nas simulações) assumem os mesmos patamares, validando, assim, o uso das tarifas segundo o trabalho mencionado para fins dessa pesquisa. 
Tabela 3. Tarifas nominais e taxa de proteção efetiva para produtos selecionados da cadeia do café no mercado da União Européia: em \%.

\begin{tabular}{|c|c|c|c|}
\hline \multirow{2}{*}{ Cadeias } & \multirow{2}{*}{ Produtos } & \multicolumn{2}{|c|}{$\mathrm{UE}(\%)$} \\
\hline & & $\mathrm{TN}$ & ERP \\
\hline \multirow{3}{*}{ Café } & Café, não torrado & 0,0 & - \\
\hline & Café, torrado & 7,5 & 13,6 \\
\hline & Café, extratos, essências e concentrados & 9,0 & 22,4 \\
\hline
\end{tabular}

Nota: TN representa as tarifas nominais e ERP representa as taxas de proteção efetivas. EU-15, tarifas de 2003. Nota: Sinais convencionais utilizados: - não se aplica dado numérico.

Fonte: Nassar, Arashiro e Jank (2007).

Tabela 4. Tarifas nominais e taxa de proteção efetiva para produtos selecionados da cadeia da soja nos mercados da União Européia e da China: em \%.

\begin{tabular}{|c|c|c|c|c|c|}
\hline \multirow{2}{*}{ Cadeias } & \multirow{2}{*}{ Produtos } & \multicolumn{2}{|c|}{ UE $(\%)$} & \multicolumn{2}{|c|}{ China $(\%)$} \\
\hline & & $\mathrm{TN}$ & ERP & $\mathrm{TN}$ & ERP \\
\hline \multirow{4}{*}{ Soja } & Grãos de soja & 0,0 & - & 3,0 & - \\
\hline & Farelo de soja & 0,0 & 0,0 & 5,0 & 17,3 \\
\hline & Óleo de soja, bruto & 3,2 & 11,8 & 9,0 & 25,2 \\
\hline & Óleo de soja, refinado & 5,1 & 14,1 & 9,0 & 19,6 \\
\hline
\end{tabular}

Nota: TN representa as tarifas nominais, e ERP representa as taxas de proteção efetivas. EU-15, tarifas de 2003 e China, de 2004.

Nota: Sinais convencionais utilizados: - não se aplica dado numérico.

Fonte: Nassar, Arashiro e Jank (2007).

Para avaliar o impacto da redução da escalada tarifária sobre o comércio de produtos processados, optou-se por um modelo de equilíbrio parcial destinado a estimar os efeitos de alterações de política comercial tais como as tarifas no caso da presente pesquisa.

Análises de equilíbrio parcial geralmente enfocam somente um setor (ou produto) da economia, assumindo que o impacto daquele setor sobre o resto da economia é pequeno ou mesmo inexistente. Por exemplo, assume-se que a alteração de uma política em um mercado específico, somente afeta o preço naquele setor, desconsiderando-se os efeitos renda em outros mercados. A escassez de recursos de uma economia também não é levada em consideração. Dessa forma, análises de equilíbrio parcial mostram-se mais adequadas quando o interesse do estudo é uma política setorial, ou quando o setor em questão representa somente uma pequena parcela do total da renda, e ainda quando as alterações simuladas podem alterar o preço em um único mercado (PIERMARTINI e TEH, 2005).

Os modelos de equilíbrio parcial têm a vantagem de possibilitar o tratamento do problema com um nível de detalhamento que não é factível empregando- 
-se outra metodologia, como por exemplo, modelos de equilíbrio geral. Em se tratando de uma análise da escalada tarifária, os modelos de equilíbrio geral dificilmente se prestam à análise da diferença entre as tarifas dos produtos em diferentes níveis de processamento pela forma da construção da base de dados (ou seja, produtos primários e processados de uma mesma cadeia em geral estão agrupados em um mesmo setor, dificultando uma análise individual dos produtos. Além disso, as tarifas usadas nos modelos de equilíbrio geral tendem a ser taxas médias, impossibilitando a análise de linhas tarifárias específicas tal como requer o estudo da escalada tarifária. Mattos (1989) representa importante contribuição nessa linha de pesquisa.

A modelagem apresentada por Laird e Yeats (1986) foi escolhida para execução da pesquisa, na forma apresentada a seguir. Trata-se de uma metodologia de equilíbrio parcial que faz uso de dados de demanda de importações, tarifas e elasticidades.

A função de demanda por importação do país importador j pela commodity i produzida no país $k\left(M_{i j k}\right)$ é função da renda do país $j\left(Y_{j}\right)$, o preço doméstico do bem i $\left(P_{i j j}\right)$ e o preço do bem i vendido em j e produzido em $\mathrm{k}\left(P_{i j k}-\right.$ preço de importação) e é expressa da seguinte forma:

$$
M_{i j k}=f\left(Y_{j}, P_{i j j}, P_{i j k}\right)
$$

A função de oferta de exportação do país produtor/exportador $k$ da commodity $i$ para o país $j\left(X_{i k j}\right)$, que é função do preço do bem $i$ produzido pelo país $k$ e importado pelo país $j$ ( $P_{i k j}$ - preço recebido pelo exportador), pode ser expressa da seguinte forma:

$$
X_{i k j}=f\left(P_{i k j}\right)
$$

As expressões (3) e (4) se relacionam pela seguinte identidade (no equilíbrio tem-se a igualdade entre a oferta por exportações e a demanda por importações):

$$
X_{i k j}=M_{i j k}
$$

Assumindo-se que em uma situação de livre comércio o preço doméstico da commodity $i$ no mercado do país importador $j$ será igual ao preço de exportação do país $k$ mais os custos com transporte e seguro, segue-se que esse preço aumentará em proporção equivalente à incidência ad valorem ${ }^{7}$ de tarifas ou de quaisquer distorções não tarifárias aplicadas ao produto. Ou seja, assume-se que o preço do bem $i$ praticado no país $j\left(P_{i j k}\right)$ será igual ao preço recebido pelos exportadores do país $k\left(P_{i k j}\right)$, somado às barreiras comerciais tarifárias e não tarifárias, além dos custos com transporte e seguros. Assim sendo, $t_{i j k}$ define

7 O equivalente ad valorem refere-se às incidências tarifárias, transportes, seguros e fretes, além de outros obstáculos não tarifários. 
o nível tarifário inicial do bem $i$, dado por uma tarifa ad valorem, cobrada pelo país $j$ na importação do bem $i$, proveniente do país $k$.

$$
P_{i j k}=P_{i k j}\left(1+t_{i j k}\right)
$$

Pode-se indicar ainda que as receitas com exportações recebidas por $k\left(R_{i k j}\right)$ são funções do volume exportado $\left(X_{i k j}\right)$ e do preço recebido $\left(P_{i k j}\right)$ :

$$
R_{i k j}=X_{i k j} \cdot P_{i k j}
$$

O efeito de criação de comércio $^{8}$ corresponde ao aumento de demanda no país $j$ pela commodity $i$ do país exportador $k$ resultante da redução de preço, associada à pré-suposição de transmissão completa de mudanças nos preços quando tarifas ou barreiras não tarifárias são reduzidas ou eliminadas.

Para a derivação da fórmula de criação de comércio, considera-se, primeiramente, que é possível a partir da expressão (6) obter o diferencial total do preço doméstico com relação a tarifas e preço de exportação. Supondo-se que o país $j$ diminui suas barreiras de importação, tal efeito pode ser expresso a partir da diferenciação total da referida equação para cálculo dos efeitos sobre o comércio, através da mensuração das mudanças tarifárias:

$$
d P_{i j k}=P_{i k j} \cdot d t_{i j k}+\left(1+t_{i j k}\right) d P_{i k j}
$$

Nessa equação (8), tem-se que $d t_{i j k}$ é o diferencial da tarifa $t_{i j k}$ (que pode ser aproximado pela diferença entre a tarifa final e inicial), $d P_{i j k}$ corresponde ao diferencial do preço do bem $i$ vendido no país $j$ e proveniente do país $k$ (diferencial do preço de importação); e $d P_{i k j}$ é o diferencial do preço do bem $i$ produzido no país $k$ e importado pelo país $j$ (diferencial do preço recebido pelo exportador).

Paralelamente, a expressão padrão para elasticidade de demanda por importação com relação ao preço de importação $\left(E m_{i j}\right)$ pode ser rearranjada como segue:

$$
\frac{d M_{i j k}}{M_{i j k}}=E m_{i j} \cdot\left(\frac{d P_{i j k}}{P_{i j k}}\right)
$$

8 Um segundo efeito de variação de política comercial é o chamado desvio de comércio, geralmente usado para quantificar a tendência de importadores para substituir bens de uma fonte em detrimento de outra em resposta a variação nos preços de importação dessa fonte e não das alternativas. Desvios de comércio em geral são estudados no caso da introdução ou eliminação de tratamento preferencial para produtos originários de um país enquanto se mantém inalterado o tratamento para com bens de outras fontes. Nessa pesquisa, porém, foram somente contabilizados impactos de criação e não desvio de comércio. 
Substituindo-se as expressões (6) e (8) na expressão 9, tem-se que:

$$
\frac{d M_{i j k}}{M_{i j k}}=E m_{i j} \cdot\left(\frac{d t_{i j k}}{\left(1+t_{i j k}\right)}+\frac{d P_{i k j}}{P_{i k j}}\right)
$$

Simultaneamente, a expressão padrão para elasticidade de oferta de exportação com relação ao preço mundial $\left(E x_{i k}\right)$ pode ser assim expressa como:

$$
\frac{d P_{i k j}}{P_{i k j}}=\frac{\left(\frac{d X_{i k j}}{X_{i k j}}\right)}{E x_{i k}}
$$

A partir da expressão (5) segue que:

$$
\frac{d M_{i j k}}{M_{i j k}}=\left(\frac{d X_{i k j}}{X_{i k j}}\right)
$$

Substituindo-se a expressão (12) em (11), chega-se à seguinte expressão:

$$
\frac{d P_{i k j}}{P_{i k j}}=\frac{\left(\frac{d M_{i j k}}{M_{i j k}}\right)}{E x_{i k}}
$$

Substitui-se, então, a expressão (13) na expressão (10), fazendo surgir, a partir de um rearranjo dos fatores, a fórmula que define o cálculo dos efeitos de criação de comércio.

$$
\begin{aligned}
& \frac{d M_{i j k}}{M_{i j k}}=E m_{i j}\left(\frac{d t_{i j k}}{\left(1+t_{i j k}\right)}+\frac{\frac{d M_{i j k}}{M_{i j k}}}{E x_{i k}}\right) \\
& \frac{d M_{i j k}}{M_{i j k}}-\frac{E m_{i j}}{E x_{i k}}\left(\frac{d M_{i j k}}{M_{i j k}}\right)=E m_{i j}\left(\frac{d t_{i j k}}{\left(1+t_{i j k}\right)}\right) \\
& \frac{d M_{i j k}}{M_{i j k}}-\frac{E m_{i j}}{E x_{i k}}\left(\frac{d M_{i j k}}{M_{i j k}}\right)=E m_{i j}\left(\frac{d t_{i j k}}{1+t_{i j k}}\right)
\end{aligned}
$$

A expressão para a criação de comércio $\left(T C_{i j}\right)$ pode ser então escrita como segue:

$$
d M_{i j k}=T C_{i j k}=\frac{M i_{j k} \cdot E m \cdot \frac{d t_{i j k}}{\left(1+t_{i j k}\right)}}{1-\frac{E m}{E x}}
$$

Deve-se notar que, nos casos em que a elasticidade de oferta de exportação com relação ao preço mundial pode ser considerada infinita, o denominador da expressão (17) torna-se unitário e pode ser ignorado. Essa consideração é importante, uma vez 
que é plausível admitir que a elasticidade da oferta de exportações tende a infinito no caso em que as exportações não apresentam grande expressão relativamente ao total da produção do país em questão. Quando esse é o caso, não se identificam efeitos dos preços sobre as exportações, e consequentemente, a receita aumenta na proporção do aumento no volume das exportações.

Portanto, a fórmula de criação de comércio empregada neste artigo define que uma redução tarifária induz uma variação no preço de um bem vendido no mercado de um país importador ${ }^{9}$. Esta variação, multiplicada pela elasticidade-preço da demanda de importação deste bem e pelo valor das importações no ano base, resulta na variação do total importado.

Para a simulação dos impactos comerciais das simulações de alterações na política comercial da União Européia no caso de produtos selecionados do café e da soja, e da China, no caso da soja, foram coletados dados de comércio no ano base de 2007. Estes estão resumidos nas Tabelas 1, 2 e 3 do Apêndice.

Para a quantificação dos impactos comerciais de eliminação e de uma redução da escalada tarifária foram empregados dados de elasticidade-preço da demanda por importação conforme indicações na Tabela 5. Exemplificando-se com o caso do óleo de soja na UE, a elasticidade-preço da demanda por importação define que uma redução de $1 \%$ no preço de importação (preço CIF mais tarifas) significaria um aumento de $0,31 \%$ das importações.

Tabela 5. Elasticidades-preço de demanda por importação em mercados e produtos selecionados.

\begin{tabular}{cc}
\hline Mercados/Produtos & Valor \\
\hline UE* & $-0,015$ \\
Soja em grãos & $-0,64$ \\
Farelo & $-0,31$ \\
Óleo de soja & \\
China* & $-0,15$ \\
Soja em grãos & $-0,01$ \\
$\quad$ Farelo & $-0,06$ \\
Óleo de soja & \\
UE & $-0,05$ \\
Café não torrado** & $-0,20$ \\
Café torrado*** & $-0,20$ \\
Café solúvel*** & \\
\hline
\end{tabular}

Fonte: * Costa, Xia e Rosson (2007). ${ }^{* *}$ Niemi, Huan-Niemi, Ledebur, Salamon (2005). ${ }^{* * *}$ Koning, Calo e Jongeneel (2004).

9 Lembrar que uma variação no preço em função de uma variação nas tarifas é dada por: $\Delta P_{i j k}=\frac{P_{i k j}\left(1+t_{1 i j k}\right)-P_{i k j}\left(1+t_{0 i j k}\right)}{P_{i k j}\left(1+t_{0 i j k}\right)}$ 


\section{Resultados}

\subsection{Redução da Escalada tarifária sob a Rodada Doha}

O primeiro passo para a execução do objetivo proposto consistiu na simulação de uma redução da escalada tarifária, segundo o que vem sendo negociado na Rodada Doha de negociações multilaterais. A proposta em negociação quanto à redução da escalada tarifária em Doha sugere cortes tarifários maiores sobre produtos processados do que sobre os de menor grau de processamento ao longo de uma cadeia produtiva, quando se considera um conjunto de cadeias selecionadas.

No caso do mercado de café na União Européia, por exemplo, a tarifa nominal incidente sobre a importação de café verde é nula, assumindo uma taxa de 7,5\% para café torrado e de 9\% para o café solúvel. Com a incidência dos cortes sugeridos para reduzir a escalada tarifária, as tarifas sobre o café torrado e café solúvel passam, respectivamente, a 3,2\% e 3,9\% (Tabela 6).

No caso da soja na União Européia, as tarifas nominais sobre a importação de grão e de farelo são nulas. Sobre a importação de óleo de soja bruto, a tarifa incidente é de 3,2\%, e de 5,1\% no caso do óleo refinado. Aplicando-se os cortes sugeridos nas negociações da Rodada Doha, as tarifas incidentes sobre os óleos passariam a $1,4 \%$ e $2,2 \%$, respectivamente.

No mercado chinês, a tarifa sobre o grão de soja é de 3\%. Para o farelo de soja, a tarifa de importação é de $5 \%$, e sobre os óleos (tanto bruto quanto refinado), de $9 \%$. Após a aplicação de corte tarifário para redução da escalada tarifária, a tarifa nominal de importação sobre o grão de soja se reduziria para $2 \%$, a incidente sobre o farelo ficaria em 3,1\% e sobre os óleos, cairia para 5,6\% (Tabela 6).

A Tabela 6 resume as informações sobre as tarifas prevalecentes segundo linhas tarifárias para os produtos e mercados, sendo analisados juntamente aos percentuais de cortes propostos segundo uma fórmula geral e segundo cortes para eliminação de escalada tarifária propostos na Rodada Doha. As tarifas resultantes após a aplicação dos cortes sugeridos também são apresentadas.

Considera-se a definição de escalada tarifária como a diferença entre as tarifas nominais, ou tariff wedge, conforme definido na equação (1). Essa definição é empregada para comparar o impacto da redução tarifária sobre a escalada tarifária quando se considera a redução. Os dados indicados na Tabela 7 sugerem a redução efetiva dessa diferença após a aplicação dos cortes, tanto quando se emprega o corte segundo fórmula geral, quanto os cortes visando impedir a ocorrência de escaladas tarifárias.

Os resultados ilustrados na Tabela 7 também indicam que, no caso do mercado de café na União Européia, a escalada tarifária entre o café torrado e o café não torrado diminuiria de 7,5 pontos percentuais (pp) para 3,2. A escalada tarifária entre o café solúvel e o café não torrado passaria de 9 para 3,9 pp. Ainda no mercado europeu, a escalada tarifária incidente sobre o óleo de soja bruto em relação ao grão de soja cairia para de 3,2 para 1,4 pp, e no caso do óleo refinado, de 5,1 para $2,2 \mathrm{pp}$. 

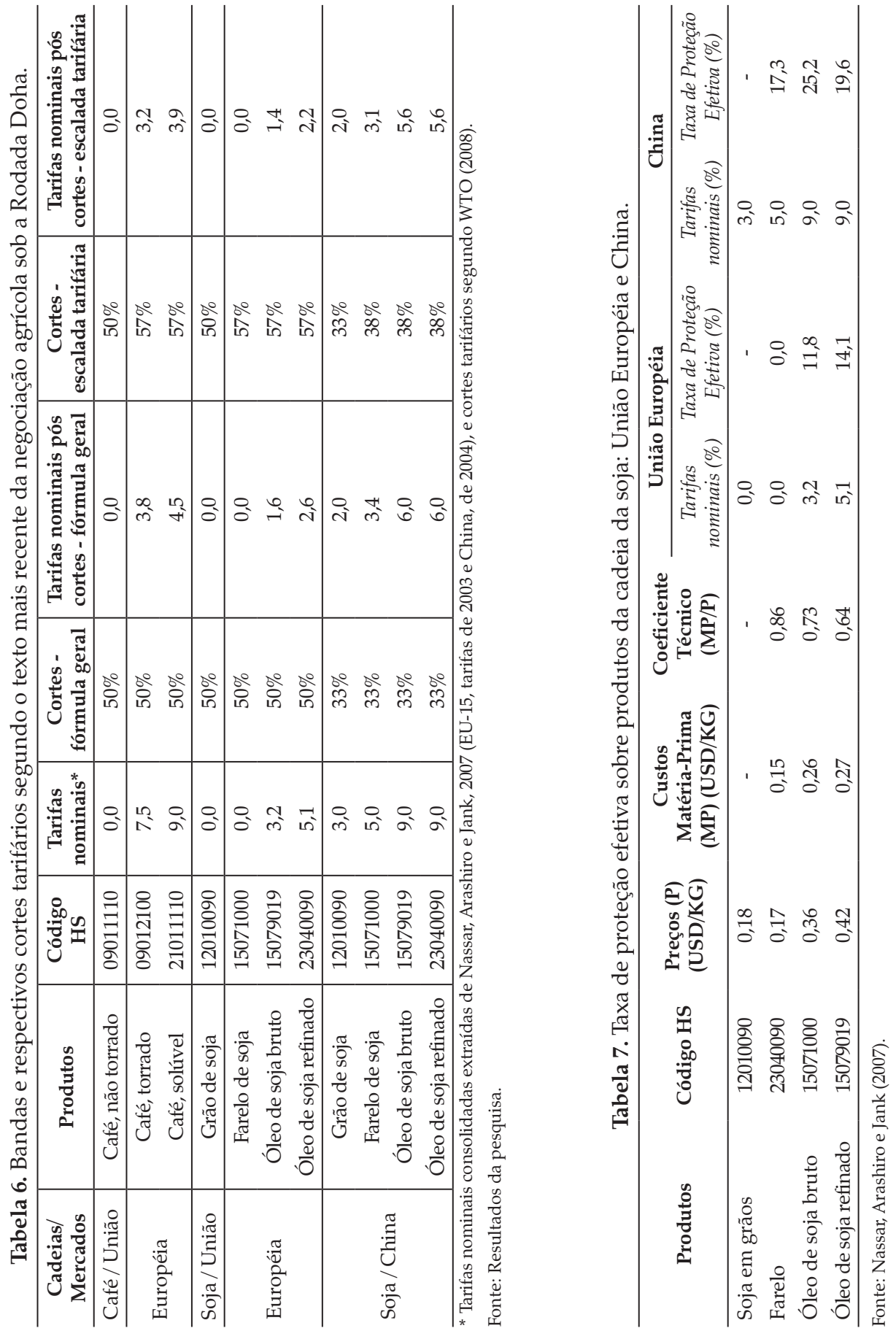

RESR, Piracicaba, SP, vol. 49, no 02, p. 295-322, abr/jun 2011 - Impressa em julho 2011 
No mercado da China, a escalada tarifária do farelo em relação ao grão de soja passaria de 2,0 para 1,1 pp. No caso dos óleos de soja, tanto bruto quanto refinado, a escalada tarifária em relação à soja em grão cairia de 6,0 para 3,6 pp (Tabela 6).

A verificação de mudanças nas tarifas nominais em termos das taxas de proteção efetiva é adequada para avaliar a real proteção que a estrutura tarifária proporciona às indústrias de processamento domésticas nos países importadores. Esses valores servem como base para analisar os impactos da redução tarifária proposta em Doha sobre a proteção efetiva nos mercados e produtos selecionados.

Embora as tarifas nominais incidentes sobre a importação de óleo de soja pelo mercado europeu sejam relativamente baixas (3,2\% para óleo bruto e $5,1 \%$ para óleo refinado), as taxas efetivas de proteção chegam a 11,8\% e 14,1\%, respectivamente (Tabela 6). No mercado da China, a proteção é ainda maior. As taxas de proteção efetiva chegam a 17,3\% na importação do farelo de soja, 25,2\% no caso do óleo bruto e 19,6\% sobre o óleo refinado. Essas taxas foram extraídas de Nassar, Arashiro e Jank (2007), que, por sua vez, utilizaram os parâmetros resumidos na Tabela 6 .

Notas para cálculo dos coeficientes técnicos e custos: - 1 tonelada de soja produz 0,775 tonelada de farelo e 0,19 tonelada de óleo bruto; 1 tonelada de óleo bruto produz 0,980 tonelada de óleo refinado; - No caso do farelo tem-se que descontar a receita do óleo bruto; - No caso do óleo bruto tem-se que descontar a receita do farelo; - No caso do óleo refinado tem-se que descontar a receita do farelo $\left(\mathrm{ICONE}^{10}\right)$.

Os impactos da redução tarifária sugerida sob a Rodada Doha sobre a proteção efetiva também foram analisados, sendo os resultados apresentados na Tabela 8. No mercado europeu verifica-se que as taxas de proteção efetiva sobre os óleos podem ser reduzidas para 5,2\% (bruto) e 6,1\% (refinado) (Tabela 8). Isso corresponde a uma queda em torno de $56 \%$ na proteção efetiva incidente sobre os óleos de soja na União Européia. No mercado da China, a taxa de proteção efetiva sobre o farelo cairia para 9,8\%, sobre o óleo de soja bruto, para 15,3\%, e para $12 \%$ no caso do óleo de soja refinado (Tabela 8). Essa alteração resultaria em reduções na taxa de proteção efetiva sobre o farelo, óleo bruto e óleo refinado na China de $42,9 \%, 39,2 \%$ e $38,9 \%$, respectivamente.

No caso do mercado europeu de café, as tarifas nominais incidentes sobre o café torrado e o café solúvel são de 7,5\% e 9\%, respectivamente. Já as taxas efetivas de proteção atingem patamares mais elevados: 13,6\% sobre o café torrado e $22,4 \%$ sobre o café solúvel (Tabela 9).

10 Dados não publicados. 

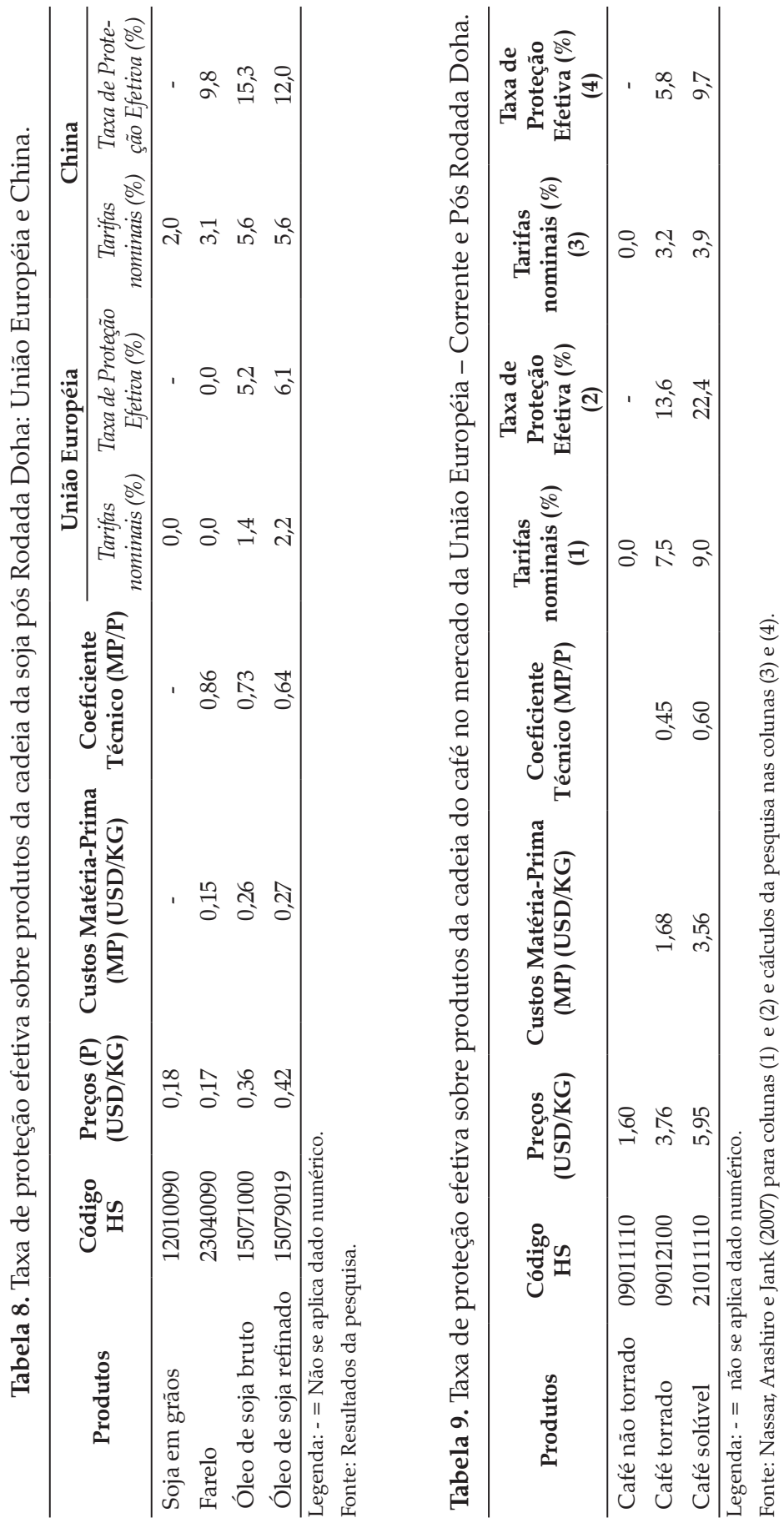

RESR, Piracicaba, SP, vol. 49, no 02, p. 295-322, abr/jun 2011 - Impressa em julho 2011 

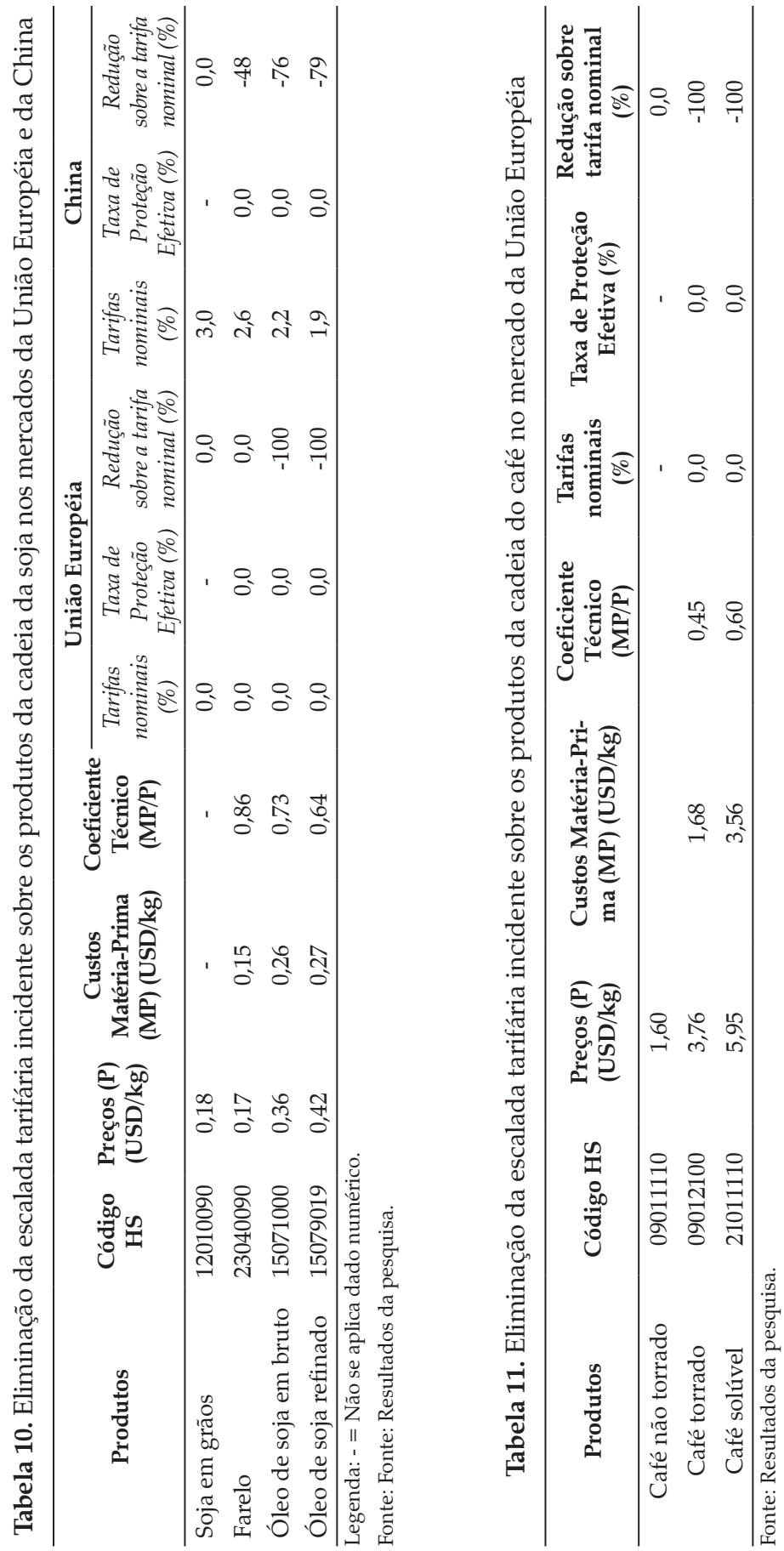

RESR, Piracicaba, SP, vol. 49, no 02, p. 295-322, abr/jun 2011 - Impressa em julho 2011 
A redução tarifária proposta nas negociações multilaterais sob a Rodada Doha acarretaria nos seguintes impactos em termos de proteção efetiva: 5,8\% sobre o café torrado e 9,7\% sobre o café solúvel (Tabela 9). Essa alteração, por sua vez, resultaria em redução na taxa de proteção efetiva que o mercado europeu tem aplicado sobre o café torrado e solúvel, para 57,3\% e 56,7\% respectivamente.

\subsection{Eliminação da escalada tarifária}

Nessa seção são apresentadas as tarifas nominais resultantes da eliminação da escalada tarifária em termos das taxas de proteção efetiva.

No caso da soja na União Européia, a eliminação da escalada tarifária requer tarifas nominais nulas sobre os óleos considerando-se as tarifas nominais já nulas sobre a soja em grãos bem como sobre o farelo. Já no mercado chinês, mantendo-se as tarifas nominais de $3 \%$ sobre a soja em grãos, deveriam incidir $2,6 \%$ sobre o farelo, $2,2 \%$ sobre o óleo de soja bruto e $1,9 \%$ sobre o óleo de soja refinado (Tabela 10 ).

Dessa forma, considerando-se as tarifas de importação correntes, as reduções tarifárias necessárias para o fim da escalada tarifária seriam as indicadas na Tabela 10. As tarifas incidentes sobre os óleos de soja no mercado europeu deveriam ser reduzidas em $100 \%$. Já no mercado da China, as reduções tarifárias deveriam ser de $48 \%$ sobre a tarifa incidente no farelo, $76 \%$ no caso do óleo de soja bruto e $79 \%$ no caso do óleo de soja refinado. Em qualquer um dos casos, portanto, a redução tarifária necessária para a eliminação da escalada tarifária consiste em patamares de corte mais elevados do que aqueles sugeridos no texto de negociação agrícola mais recente sob a Rodada Doha.

Entre os produtos da cadeia do café no mercado europeu, as tarifas nominais sobre o café torrado e solúvel precisariam ser nulas para o fim da escalada tarifária, demandando, dessa forma, cortes tarifários de 100\%, bem acima dos cortes propostos sob Doha (Tabela 11).

\subsection{Impactos comerciais da redução e eliminação da escalada tarifária sob Rodada Doha}

A quantificação dos impactos comerciais de redução e eliminação da escalada tarifária foi realizada considerando-se que uma redução tarifária provoca uma variação no preço de um bem selecionado vendido em um país importador, que, multiplicada pela elasticidade-preço da demanda de importação deste bem e pelo valor das importações no ano base, resulta em uma variação do total importado.

A Tabela 12 ilustra os resultados da pesquisa acerca dos impactos comerciais de redução e eliminação da escalada tarifária incidente sobre produtos do café no mercado da UE e produtos da soja no mercado da China e da UE. Em todos 
os casos, a variação percentual de aumento, bem como o incremento em termos nominais, se aplica em relação ao valor/volume das importações dos mercados em análise dos produtos brasileiros no ano base de 2007, com exceção do farelo na China ano base 2006.

Ao simular a redução da escalada tarifária conforme proposta em negociação sob Doha, as importações de café torrado no mercado da União Européia de produtos originários do Brasil aumentariam em 11,4\%, o que equivale a US\$ 576,7 mil. As importações de café solúvel, por sua vez, teriam o mesmo aumento percentual de $11,4 \%$, com incremento em US\$ 10,1 milhões. Vale lembrar que sobre o café não torrado não incidem tarifas, daí a ausência de impactos comerciais para tal produto. O cenário que considera a eliminação da escalada tarifária traz impactos ainda maiores. A variação positiva resultante é de $20 \%$ nas importações de café torrado e solúvel, representado aumentos de US\$1,01 e US\$17,7 milhões, respectivamente.

Na cadeia da soja no mercado europeu, a tarifa sobre as importaçóes de soja em grãos e para o farelo é nula, de forma que não se analisam aqui impactos comerciais de mudança tarifária. No cenário de redução da escalada tarifária, as importações de óleo de soja bruto e refinado com origem no Brasil cresceriam em $17,7 \%$, o que representa incrementos de US\$ 23,8 e US\$ 60,2 milhões, respectivamente. Alternativamente, a simulação de eliminação da escalada tarifária proporcionaria crescimento de $31 \%$ nas importações de óleo de soja, bruto e refinado, equivalente a elevações de US\$ 41,9 e US\$ 105,7 milhões, respectivamente.

No mercado da China, a redução da escalada tarifária segundo Doha traria $5 \%$ de aumento nas importações de soja em grãos originárias do Brasil (US \$ 192,7 milhões), 0,4\% nas importações de farelo (US\$ 56,2 mil) e 2,3\% nas importações de óleo de soja, tanto bruto (US\$ 7,1 milhões) quanto refinado (US\$ 75,9 mil). A eliminação da escalada tarifária proporcionaria impactos mais acentuados: 0,5\% nas importações de farelo (US\$ 71,7 mil), 4,5\% nas importações de óleo de soja bruto (US\$ 14,1 milhões), e 4,7\% nas importações de óleo de soja refinado (US\$ 157,3 mil). Não haveria impactos sobre o comércio de soja em grãos, uma vez que as tarifas nominais incidentes se manteriam inalteradas. 


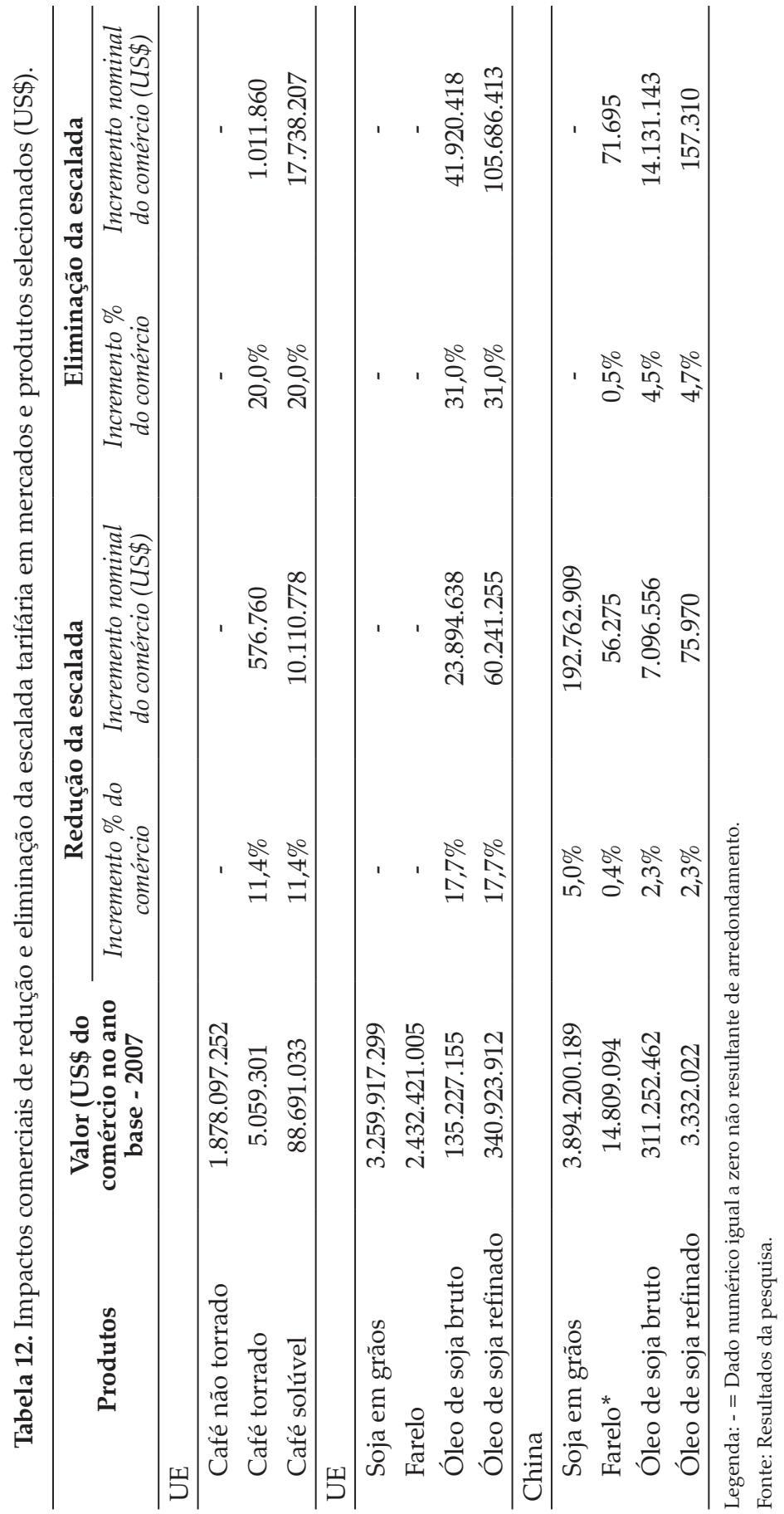


Vale uma discussão com relação aos impactos comerciais verificados no mercado da China sobre os produtos da soja no caso da redução das tarifas segundo Doha. A modelagem indicou impactos comerciais positivos sobre o volume de importação de grãos de soja, o que é coerente com o método empregado que determina que uma redução nas tarifas acarrete em aumento no comércio. No entanto, essa elevação das importações de grãos poderia ser questionada, tendo em vista que o objetivo de redução da escalada tarifária é ampliar o comércio de processados em detrimento do comércio de primários. Assim sendo, esse resultado ilustrado corresponde a uma indicação obtida a partir do uso do modelo de impactos comerciais empregado. Na prática, por sua vez, esses resultados poderiam se mostrar subestimados considerando-se unicamente o aumento das exportações de produtos processados da soja, tais como farelo e óleo em substituição à soja em grãos.

Em contrapartida, a simulação de eliminação da escalada tarifária trouxe impactos mais coerentes no sentido da substituição das importações de primários por produtos processados das cadeias nos mercados analisados.

Assim sendo, é interessante apontar como os impactos comerciais se ampliam com a simulação de eliminação da escalada tarifária em relação à redução proposta sob Doha. A Tabela 12 ilustra o incremento percentual e em valor dos resultados indicados no cenário de fim da escalada tarifária em relação ao de redução segundo Doha.

No mercado da União Européia, o aumento das importações dos produtos da cadeia do café e da soja seria 75,4\% maior numa situação de eliminação do que na situação de redução da escalada tarifária, conforme proposta em negociação sob Doha. No caso do café torrado, a eliminação proporcionaria aumento de US\$ 435,1 mil no impacto comercial sugerido pela simples redução. No caso do café solúvel, esse aumento seria de US\$ 7,6 milhões. Sobre os impactos no comércio de óleo de soja, esses seriam de US\$ 18 milhões a mais no caso do óleo bruto e de US\$44,5 milhões a mais no caso do refinado.

Já no mercado da China, a diferença entre os impactos de eliminação e redução da escalada tarifária seria de: $27,4 \%$ no caso do farelo (US\$ 15,4 mil a mais), quase $100 \%$ no caso do óleo de soja bruto (US\$ 7 milhões a mais) e 107\% no caso do óleo de soja refinado (US\$ 81,3 mil a mais).

Em termos de volume comercializado, pôde-se também identificar os impactos. O café torrado no mercado europeu teria importações acrescidas de 127 toneladas no caso da redução da escalada tarifária e 224 toneladas no caso da eliminação da mesma. No primeiro caso, isso representaria $11,4 \%$ de aumento e, no segundo caso, 20\% . Já as importações de café solúvel aumentariam em 1,5 mil (ou 11,4\%) e 2,7 mil toneladas (ou 20\%) na simulação de redução e eliminação da escalada tarifária, respectivamente. As importações de óleo de soja bruto seriam acrescidas de aproximadamente 33 mil toneladas na situação de redução da escalada tarifária, e de 57,8 mil toneladas considerando-se a eliminação da escalada tarifária. Por 
sua vez, o aumento das importações de óleo de soja refinado seria de 76,8 mil e 134,8 mil toneladas, na situação de redução e eliminação da escalada tarifária, respectivamente. Por fim, no mercado da China, o incremento das importações de produtos da soja, nos casos de redução e eliminação da escalada tarifária, seria de: 271 e 345 toneladas de farelo, 9 mil e 18,1 mil toneladas de óleo de soja bruto, e 109 e 226 toneladas de óleo de soja refinado.

No caso da soja, os impactos comerciais resultantes das simulações de redução/ eliminação da escalada tarifária, em particular no que se refere ao comércio de produtos processados da cadeia, se mostraram maiores para o mercado europeu do que para o chinês. Isso se deve, em parte, às maiores elasticidades consideradas no mercado europeu bem como às mais elevadas taxas de corte tarifário simuladas nesse mercado, considerando-se que a China é um país em desenvolvimento.

\section{Considerações Finais}

Os resultados obtidos dificultam a generalização de que são os países desenvolvidos que empregam a escalada tarifária para desestimular as exportações de produtos processados oriundas de países em desenvolvimento. No caso dos resultados apresentados no presente artigo, apesar dos impactos comerciais da eliminação da escalada serem maiores no mercado europeu, a escalada tarifária imposta pela China mostrou-se mais prejudicial às exportações brasileiras de produtos da soja do que aquela vigente no mercado europeu. Isto é identificado pelo fato de que o comércio dos produtos do complexo soja do Brasil com a China compreende $92 \%$ de grãos e, do Brasil com a UE a participação dos grão é de $52 \%$ (ambos os dados referente ao ano base de 2007).

No que se refere aos possíveis impactos internos dessa elevação nas exportações de produtos processados, parece plausível considerar que um incremento das exportações de produtos processados das cadeias em análise certamente beneficia as indústrias processadoras nacionais. Para os consumidores domésticos desses produtos, no entanto, os impactos podem (ou não) ser negativos, dependendo do tamanho da indústria nacional, entre outros fatores. Em situação em que prevalece a capacidade ociosa, por exemplo, a ampliação das exportações de produtos processados pode não representar menor oferta doméstica, nem tampouco elevação de preços internos sobre produtos tais como óleo de soja e farelo para ração. Essa discussão pode, portanto, ser aprimorada e avaliada com maiores detalhes em pesquisa complementar.

A análise conduzida mostra que embora não elimine a distorção, o sistema de cortes tarifários proposto nas negociações da Rodada Doha da OMC pode reduzir a escalada tarifária com impactos positivos para as exportações brasileiras de produtos processados do café e da soja nos mercados importadores 
analisados. No entanto, os incrementos às exportações brasileiras de produtos processados mostram-se mais expressivos a partir da eliminação da escalada tarifária. Dessa maneira, a fórmula e os cortes simulados para a redução das tarifas de importação servem de parâmetro para a análise das decisões que virão a ser tomadas no âmbito da $\mathrm{OMC}$, em particular no que se refere à escalada tarifária, distorção focada no presente estudo.

O trabalho mostra ainda que, no mercado da soja, a escalada tarifária aplicada pela China é mais restritiva que a escalada tarifária prevalecente no mercado da União Européia. Dessa forma, não se deve generalizar a proposição de que países desenvolvidos são responsáveis pelos maiores desestímulos à importação de produtos processados.

Outro aspecto que pode ser ressaltado a partir dos resultados das simulações é que um tratamento diferenciado para países em desenvolvimento, que prevê reduções tarifárias menores e/ou maior prazo para implantar mudanças, pode não ser uma estratégia efetivamente interessante. Os resultados ilustram que, em determinados contextos, a diferenciação pode prejudicar ao invés de beneficiar os países de uma mesma categoria. Nota-se que a escalada tarifária imposta pela China, um país em desenvolvimento, é mais restritiva às exportações brasileiras de produtos processados da soja do que aquela imposta pela UE, um bloco de países desenvolvidos. Dessa forma, conforme mencionado acima, o tratamento diferenciado nas negociações comerciais, geralmente defendido pelos países em desenvolvimento, pode não ser uma estratégia interessante para o Brasil no contexto analisado.

Cabe ressaltar ainda que, embora a escalada tarifária possa ser identificada como um dos fatores que prejudica a competitividade das exportações brasileiras de produtos processados das cadeias analisadas, a análise conduzida não tem o objetivo de esgotar a identificação de fatores que comprometem a agregação de valor na pauta exportadora brasileira. Dessa forma, análises complementares podem ser sugeridas incorporando outras medidas não tarifárias para avaliar o impacto efetivo das restrições ao comércio de produtos com maior valor adicionado. Sabe-se que no comércio internacional atuam outras formas de entraves que não foram consideradas no presente estudo, tais como as barreiras não tarifárias, como quotas, requisitos técnicos e sanitários de importação e outros. Além disso, fatores internos ligados às opções políticas e econômicas de um país têm impacto direto sobre a estrutura produtiva e a pauta exportadora do mesmo. Questões burocráticas, ambiente regulatório, corrupção, infraestrutura interna podem, na ausência da escalada tarifária nos mercados importadores, continuar freando as exportações de produtos processados das nações em geral. Nesse sentido, análises complementares poderiam investigar quais são as evidências de que, mesmo na ausência da escalada tarifária, haveria de fato maiores condições de países produtores de commodities se beneficiarem do comércio de produtos agrícolas processados. Estudos específicos caso a caso (cadeias e mercados) 
também podem ser interessantes para identificar as limitações internas e externas existentes sobre a competitividade de cada segmento industrial.

\section{Referências Bibliográficas}

BALASSA, B. Tariff protection in industrial countries: an evaluation. Journal of Political Economy, Chicago, v. 73, n. 6, p. 573-594, 1965. Disponível em: < http:// links.jstor.org/sici?sici $=00223808 \% 28196512 \% 2973 \% 3$ A6\%3C573\%3ATPIICA $\%$ 3E2.0.CO $\% 3 \mathrm{~B} 2-\mathrm{X}>$.

BURMAN, C.; JOHANSSON, K.; KARLSSON, A.; LOXBO, H.; NORELL, B.; MATTSSON, Y.; WILHELMSSON, M. Tariff escalation for agricultural and fishery products. Jönköping: Swedish Board for Agriculture, 2001. 73 p. (Report 2001:12). Disponível em: < http://www.jordbruksverket.se/download/18.7502f61001ea08a 0c7fff128742/tariff_escalation_hela.pdf $>$.

CORDEN, W.M. The structure of a tariff system and the effective protective rate. The Journal of Political Economy, Chicago, v. 74, n. 3, p. 221-237, June 1966. Disponível em: <http://links.jstor.org/sici?sici=0022$3808 \% 28196606 \% 2974 \% 3$ A3\%3C221\%3ATSOATS\%3E2.0.CO\%3B2-G> .

COSTA, R.; XIA, Y.; ROSSON, P. An assessment of the global soybean industry: an application of stochastic equilibrium displacement model. In: SOUTHERN AGRICULTURAL ECONOMICS ASSOCIATION ANNUAL MEETING, 2007, Mobile. Selected papers... Athens: Southern Agricultural Economics Association, 2007. 20 p. Disponível em: < http://ageconsearch.umn.edu/handle/34953>.

ELAMIN, N.; KHAIRA, H. Tariff escalation in agricultural commodity markets. In: FAO. Commodity market review 2003-2004. Rome: FAO, 2003. p. 101-120. Disponível em: <http://www.fao.org/documents/show_cdr.asp?url_file=/ DOCREP/006/Y5117E/y5117e0e.htm>.

KONING, N.; CALO, M.; JONGENEEL, R. Fair trade in tropical crops is possible: international commodity agreements revisited. Wageningen, 2004. (Wageningen UR North-South Centre Discussion Paper, 3). Disponível em: < http://www. agricultures-durables-solidaires.org/ImgPageHTML/FairTrade1.do>.

LAIRD, S.; YEATS, A. The UNCTAD trade policy simulation model: a note on the methodology, data and uses. Geneva: UNCTAD, 1986. 33 p. (Discussion Papers, 19). Disponível em: < http://vi.unctad.org/tda/background/Partial\%20 Equilibrium \%20Models\%20-\%20SMART/SMART.pdf $>$.

LINDERT, P.; PUGEL, T. International economics. 10. ed. Chicago: Irwin Publishers, 1996. $123 \mathrm{p}$. 
LINDLAND, J. The impact of the Uruguay round on tariff escalation in agricultural products. Rome: FAO, Commodities and Trade Division, 1997. 78 p. Disponível em: <http://www.fao.org/documents/advanced_s_result. asp?QueryString=Lindland $+1997>$.

MATTOS, R. S. . Implicações do problema da escalada tarifária para países desenvolvidos e em desenvolvimento: uma nova metodologia de análise. Rio de Janeiro: FUNCEX - Fundação Centro de Estudos do Comércio Exterior (TDI 17), 1989 (Texto para Discussão).

NASSAR, A.M.; ARASHIRO, Z.; JANK. M.S. Tariff escalation and tariff spikes. In: KERR, W. A.; GAISFORD, J.D. (Org.). Handbook on international trade policy. London: Edward Elgar, 2007. Chap. 20, p. 222 - 236.

NIEMI, J.; HUAN-NIEMI, E.; VON LEDEBUR, O.; SALAMON, P. Expansion of Mercosur's agricultural exports to the EU: an empirical assessment of the trade flows. In: CONGRESS OF THE EUROPEAN ASSOCIATION OF AGRICULTURAL ECONOMISTS, 11., 2005, Copenhagen. Papers... The Hague: European Association of Agricultural Economists - EAAE, 2005. Disponível em: $<$ http://ageconsearch.umn.edu/bitstream/24606/1/cp05ni02.pdf

ORGANIZATION FOR ECONOMIC CO-OPERATION AND DEVELOPMENT - OCDE. Tariffescalation and environment. Paris, 1996. (OCDE/GD, 171). Disponível em: < http://www.oecd.org/dataoecd/32/32/2404858.pdf > .

PIERMARTINI, R.; TEH, R. Demystifying modelling methods for trade policy. Geneva: World Trade Organization, 2005. (Discussion Paper, 10). Disponível em: $<$ http://www.wto.int/english/res_e/booksp_e/discussion_papers10_e.pdf $>$.

UNITED NATIONS CONFERENCE ON TRADE AND DEVELOPMENT UNCTAD. Back to basics: market access issues in the Doha Agenda. Geneva, 2003. 73 p. (UNCTAD/DITC/TAB/Misc.9). Disponível em: < http://www.unctad. org/en/docs/ditctabmisc9_en.pdf >.

UNITED NATIONS. STATISTICS DIVISION. Commodity Trade Statistics Database - COMTRADE. Disponível em: < http://unstats.un.org/unsd/comtrade/default. aspx $>$.

WORLD TRADE ORGANIZATION - WTO. Committee on Agriculture Special Session. Revised draft modalities for agriculture. TN/AG/W/4/rev.3. Geneva, July 2008. Disponível em: < http://www.wto.org/english/tratop_e/agric_e/agchairtxt_ july08_e.pdf $>$. 


\section{Anexos}

Anexo 1. Importação da União Européia de produtos do café com origem brasileira em 2007 (US\$ e Kg).

\begin{tabular}{cccc}
\hline Produtos & Código HS & Valor (US\$) & Volume $(\mathrm{Kg})$ \\
\hline Café não torrado & 090111 & 1.878 .097 .252 & 778.292 .200 \\
Café torrado & 090121 & 5.059 .301 & 1.117 .600 \\
Café solúvel & 210111 & 88.691 .033 & 13.421 .239 \\
\hline
\end{tabular}

Fonte: United Nations (2008).

Anexo 2. Importação da União Européia de produtos da soja com origem brasileira em 2007 (US\$ e Kg).

\begin{tabular}{cccc}
\hline Produtos & Código HS & Valor (US\$) & Volume $(\mathrm{Kg})$ \\
\hline Soja em grãos & 120100 & 3.259 .917 .299 & 9.492 .854 .900 \\
Farelo & 230400 & 2.432 .421 .005 & 8.341 .244 .100 \\
Óleo de soja bruto & 150710 & 135.227 .155 & 186.409 .200 \\
Óleo de soja refinado & 150790 & 340.923 .912 & 434.857 .500 \\
\hline
\end{tabular}

Fonte: United Nations (2008).

Anexo 3. Importação da China de produtos da soja com origem brasileira em 2007 (US\$ e Kg).

\begin{tabular}{cccc}
\hline Produtos & Código HS & Valor (US\$) & Volume $(\mathrm{Kg})$ \\
\hline Soja em grãos & 120100 & 3.894 .200 .189 & 10.582 .105 .088 \\
Farelo * & 230400 & 14.809 .094 & 71.255 .656 \\
Óleo de soja bruto & 150710 & 311.252 .462 & 398.676 .992 \\
Óleo de soja refinado & 150790 & 3.332 .022 & 4.787 .424 \\
\hline
\end{tabular}

*: Dados de 2006.

Fonte: United Nations (2008). 